ISSN: 1948-9900

(C)2013 Science Publications

doi:10.3844/amjnsp.2013.1.12 Published Online 4 (1) 2013 (http://www.thescipub.com/ajn.toc)

\title{
Spinal Cord Injury: Current Mammalian Models
}

\author{
${ }^{1}$ Sarina Kundi, ${ }^{2}$ Roy Bicknell and ${ }^{1}$ Zubair Ahmed \\ ${ }^{1}$ Institute of Biomedical Research (West), Neurotrauma and Neurodegeneration, \\ School of Clinical and Experimental Medicine, College of Medical and Dental Sciences, \\ University of Birmingham, Room WX2.17, Edgbaston, Birmingham B15 2TT, UK \\ ${ }^{2}$ CRUK Angiogenesis Group, Institute for Biomedical Research, \\ School of Immunity and Infection, College of Medical and Dental Sciences, \\ University of Birmingham, Birmingham, B15 2TT, UK
}

Received 2012-11-04, Revised 2013-03-25; Accepted 2013-03-27

\begin{abstract}
It is estimated that approximately 2.5 million people are affected by Spinal Cord Injury (SCI), with more than 130,000 new cases reported each year (International Campaign for Cures of Spinal Cord Injury Paralysis). Although there is currently no cure for SCI, various strategies including rehabilitative, cellular and molecular therapies have been tested in a variety of animal models. But questions remain as to the validity of animal models and whether they relate to the clinical conditions found in humans. This review aims to look at the different and most current models that are used to study SCI and their potential uses in mimicking the human condition. Several different animals models have been developed to study the problems of SCI, allowing exploration of mechanisms and properties of specific pathways such as; the MAPK pathway and spinal cord diseases such as; Syringomyelia and Central Cord Syndrome to name a few to be elucidated. SCI is complicated by cavitation and a glial scar that lines the cavity, reducing the possibility of axon regeneration. Mammalian models, particularly in mice and rats, have been used for many years to study the impact of SCI and potential therapies, however, questions remain as to the validity of these models and their potential usefulness.
\end{abstract}

Keywords: Spinal Cord Injury (SCI), Cavitation, Axon Regeneration, Glial Scar, CNS

\section{INTRODUCTION}

SCI affects more than 2.5 million people worldwide and 130,000 new cases are reported each year (International Campaign for Cures of Spinal Cord Injury Paralysis). Although advances have been made through research, there are currently no fully restorative therapies for SCI and therefore, safety measures especially in the sports industry have been put in place to reduce the risk of developing any new cases (Ogungbo, 2011). SCI can lead to devastating long term effects and Methylprednisolone; the only treatment for acute human SCI (Akhtar et al., 2008) helps to reduce inflammation and pain (Gorio et al., 2005; Bracken, 2012) for the individual. The life expectancy of an individual diagnosed with SCI can be significantly reduced, impacting on their quality of life (Middleton et al., 2007; 2012), which results in income loss if the severity if the condition worsens. This further impact's on the economic burden along with the high costs associated with primary care of the individual (French et al., 2007; Nakae et al., 2011). After SCI, pathological changes at the lesion site ultimately play a part in nerve conduction loss and prolonged demyelination. These changes include increased inflammation (Zhang et al., 2012), disruption of Blood-Spinal Cord Barrier (BSCB) and

Corresponding Author: Zubair Ahmed, Institute of Biomedical Research (West), Neurotrauma and Neurodegeneration,

School of Clinical and Experimental Medicine, College of Medical and Dental Sciences,

University of Birmingham, Room WX2.17, Edgbaston, Birmingham B15 2TT, UK

Tel: +(44) 1214148858 Fax: +(44) 1214148867 
extensive haemorrhage (Echeverry et al., 2011; Lee et al., 2012) along with an increase in necrosis, apoptosis, cavitation and ischemia (Byrnes et al., 2010; James et al., 2011). An up-regulation of all these factors results in detrimental effects on axon regeneration after injury.

SCI can result from three main causes which ultimately lead to tissue damage; (1), compression caused by spinal discs or bone material pressing against the cord; (2), destruction from direct trauma; and (3), reduction in blood flow from the initial damage i.e., ischemia. SCI is a two-step process marked by distinct changes during the primary and secondary injury phases. 'Primary injury refers to damage sustained by the neural elements at the time of trauma through shear forces to axons or blood vessels and results (Cadotte and Fehlings, 2011). The secondary injury phase refers to the body's response to the primary injury and involves a host of cellular processes that occur immediately after injury and persists for months to years' (Cadotte and Fehlings, 2011). During the primary injury phase astrocytes become activated and increase the expression of GFAP as a result of the trauma sustained to the cord and fluidfilled cysts containing Extracellular Tissue Matrix (ECM) proteins such as laminin, collagen 1, 2 and 3 and fibronectin begin to appear at the lesion site. During the secondary injury phase, macrophages, monocytes and immune cells invade the lesion site in an attempt to clean up the debris in the lesion site while astrocytes increase the flow of ions from neurones to the extracellular fluids allowing astrocytes to enlarge and proliferate into the spaces provided. This reaction of the astrocytes forms the glial scar lining that surrounds cavities; a major inhibitory environment for axons (Fig. 1A and B). The injured area suffers demyelination due to a loss in oligodendrocytes and it's this prolonged demyelination that causes axonal degeneration. Along with demyelination there is also an increase in apoptosis and necrosis around the lesion site causing further detrimental effects.

SCI can be sub-divided into two main categories; complete and incomplete. According to the AASCIN (2004) neurological classification, compete SCI refers to 'no preservation of motor and/or sensory function that exists more than three segments below the level of injury, where as incomplete SCI refers to 'some preservation of motor and/or sensory function existing more than three segments below the level of the injury'.

Animal models have been developed with the aim of recreating features of either complete or incomplete SCI allowing understanding of the anatomical and biological consequences of SCI to be investigated. Animal models have several obvious advantages over their human counterpart: for example, the specified tissue needed can be used and processed for histological purposes to investigate co-localisation of proteins of interest, mRNA analysis (microarray) to give expression of proteins and protein analysis (western blotting) to give levels of protein. Rat models are most widely used to study SCI since they are inexpensive, have few surgical infections, are easy to care for and can be studied in large numbers but increasingly mouse models have also been implemented in SCI research (Nakae et al., 2011). Larger mammals such as dogs and cats are also used but very rarely and are less experienced models based in SCI research, requiring expensive after care and housing as well as stringent ethical considerations.

Currently there are range of models that are used by researchers (Table 1) that include contusion, compression and transection-based models amongst others. The limitation of these different animal models is that they can never truly express the clinical characteristics of the human condition (Davoody et al., 2011), but the real question is have animal models contributed to actual therapies? The only actual therapy for the treatment of acute SCI in humans is Methyl Prednisolone (MP) (Akhtar et al., 2008, Pandya et al., 2010) and even though it has shown a significant benefit in animal models (Merola et al., 2002) the benefits on human SCI remain unproven and is not considered a regulatory treatment for SCI (Sharma, 2012). This review aims to establish the current animal models that are used to study SCI and the advantages and disadvantages of the techniques and therefore the potential outcomes in relation to the human condition.

\subsection{Contusion Models}

The vast majority of human SCI are caused as a result of motor vehicle accidents, falls and sporting injuries involving a sudden compression of the spinal cord, resulting in vertebral damage that allows the bone or vertebral disc to encroach on the spinal canal space. Other instances include laceration of the spinal cord, bullet wounds and slow compression injuries that can result from tumour growth. The contusion model is the most widely used animal model that relies on an impactor device, such as weight-drop from a specified height. The impact of the weight can vary depending on the distance moved by the weight. The first tightly controlled contusion model of SCI was described by Allen (1911), in which a specified weight could be dropped from a defined height, delivering a defined amount of energy to the exposed spinal cord. This caused injury to the spinal cord as a result of compression and displacement and was used to study the effects of myelotomty on the outcome of SCI (Allen, 1911). 


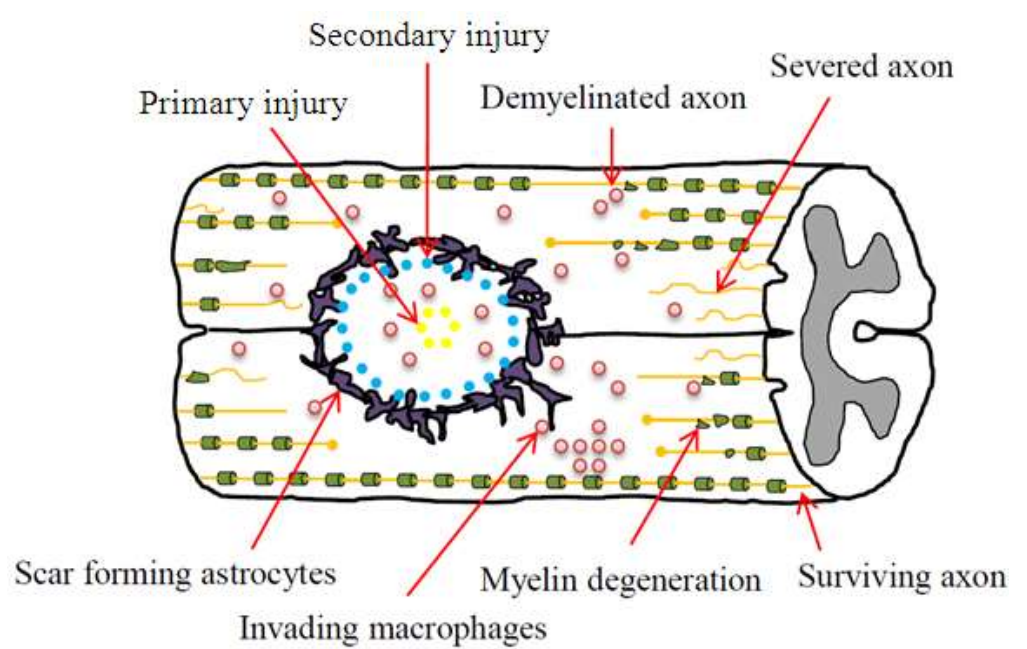

(A)

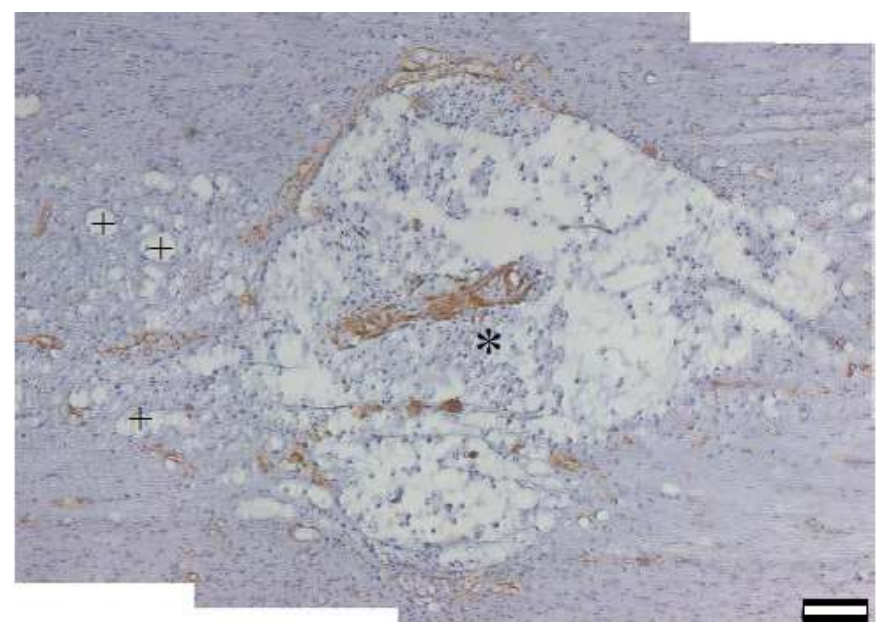

(B)

Fig. 1. The formation of cavities after SCI A. Diagrammatic representation of the formation of fluid-filled cysts after SCI. (Adapted from Springer Images www.springerimages.com/Images/Biomedicine/1-10.1007_978-3-642-02824-3_12-0), the primary injury is the initial lesion sustained to the cord causing an influx of immune cells and macrophages into the lesion site. It is the constant influx of these invading immune cells and macrophages that leads to the formation of fluid-filled cysts or cavities, which bring about the secondary injury, causing the up-regulation of reactive astrocytes that divide and fill the vacant spaces with glial scar tissue lining the cavity. The glial scar then acts as an inhibitory factor leading to myelin degradation and nerve conduction loss, (B) Longitudinal section from a T8 dorsal column crush injured rat spinal cord demonstrating laminin Immunostaining (brown) at 8 days post lesion (counterstained with Haematoxylin) and the extent of the cavitation at the lesion site, (A) large cavity is observed at the epicentre of the lesion (*) while smaller cavities are observed in adjacent areas (+). These cavities lead to destruction of axons and eventual loss of function. Scale bar $=100 \mu \mathrm{m}$

Later, a modification to this model was introduced in the form of the New York University Impactor (Gruner, 1992) and more recently the Ohio State University Spinal Cord Research Centre has produced a weight-drop device controlled by a computer to closely control a particular level of spinal cord compression (Stokes et al., 1992; Behrmann et al., 1993; Jakeman et al., 2000). A variety of slow rapid compression models have been used but it is the extent of the cord displacement that determines the severity of the injury. However, the clinical relevance of such contusion models has not been established. 
Table 1. Summary of the current SCI animal models that are used in research to mimic the clinical human SCI these animal models are used to assess pain, behaviour, histology and genetic alterations following SCI, but more importantly to assess neural and molecular outcomes. These models are more frequently developed on Rat and Mice and less frequently on larger animals such as Cats and Dogs

\begin{tabular}{|c|c|c|}
\hline Model & Description & Advantages/Disadvantages \\
\hline Contusion & $\begin{array}{l}\text { Induced with an impactor i.e. weight-drop from a } \\
\text { Specified height (Allen, 1911), thoracic contusion is } \\
\text { most commonly used (Behrmann } \text { et al., 1993; } \\
\text { Jakeman et al., 2000) Clip Induced with clips } \\
\text { calibrated to exert a force of 50/35g- }\end{array}$ & $\begin{array}{l}\text { Impact from contusion can be difficult to assess } \\
\text { pain behaviour due to variation of distance }\end{array}$ \\
\hline $\begin{array}{l}\text { Clip } \\
\text { compression }\end{array}$ & $\begin{array}{l}\text { Induced with clips calibrated to exert a force of } 50 / 35 \mathrm{~g} \\
-50 \mathrm{~g}=\text { severe response and } 35 \mathrm{~g}=\text { moderate response } \\
\text { The clip is closed over the entire cord for } 1 \text { minute } \\
\text { (Bruce } \text { et al., 2002) }\end{array}$ & $\begin{array}{l}\text { Allows for precise control of injury } \\
\text { Does not resemble injury seen in humans }\end{array}$ \\
\hline $\begin{array}{l}\text { Balloon } \\
\text { compression }\end{array}$ & $\begin{array}{l}\text { Uses different volumes of balloon inflation and } \\
\text { different compression durations of expression to } \\
\text { create contusion (Lim et al., 2007) }\end{array}$ & $\begin{array}{l}\text { Controlled environment } \\
\text { Non-invasive method of creating SCI }\end{array}$ \\
\hline $\begin{array}{l}\text { Computer } \\
\text { controlled } \\
\text { contusion }\end{array}$ & $\begin{array}{l}\text { Uses an animal trap that delivers a set weight to the } \\
\text { exposed spinal cord; the computer monitors the } \\
\text { (Stokes and Jakeman, 2002) }\end{array}$ & $\begin{array}{l}\text { Reproducible, controlled environment } \\
\text { But equipment is expensive }\end{array}$ \\
\hline $\begin{array}{l}\text { Spinal cord } \\
\text { displacement }\end{array}$ & $\begin{array}{l}\text { impact attempts to regulate trauma impact by } \\
\text { Controlling displacement length of the } \\
\text { spinal cord (Nakae et al., 2011) }\end{array}$ & $\begin{array}{l}\text { Controlled displacement and monitoring of } \\
\text { biochemical parameters at the time of impact helps } \\
\text { reduce outcome variability-controlled environment }\end{array}$ \\
\hline Transection & $\begin{array}{l}\text { Complete spinal transection, performed using spring } \\
\text { scissors (Kang et al., 2011; Nakae } \text { et al., 2011) }\end{array}$ & $\begin{array}{l}\text { Widely used to asses regeneration (Talac et al., 2004) } \\
\text { but it is clinically irrelevant (Poon et al., 2007) }\end{array}$ \\
\hline Photochemical & $\begin{array}{l}\text { The use of a dye induces the photochemical } \\
\text { reaction by activating an argon laser to produce } \\
\text { single oxygen molecules on the endothelial surface of } \\
\text { spinal cord vessels (Watson } \text { et al., 1986) }\end{array}$ & $\begin{array}{l}\text { Reliable and reproducible } \\
\text { Does not induce mechanical trauma to the cord } \\
\text { Extent of injury is difficult to control }\end{array}$ \\
\hline Excitotoxic & $\begin{array}{l}\text { Intraspinal/intrathecally injection of } \\
\text { excitotoxins e.g., quiscolic acid (Bhatoe, 2009) }\end{array}$ & $\begin{array}{l}\text { Long-lasting spontaneous pain, thermal } \\
\text { hyperalgesia and mechanical allodynia } \\
\text { (Fairbanks et al., 2000; Yezierski et al., 1998) } \\
\text { Has ability to correlate specific areas of tissue damage }\end{array}$ \\
\hline $\begin{array}{l}\text { Spinothalamic } \\
\text { tract lesions }\end{array}$ & $\begin{array}{l}\text { Lesions core pain pathway; spinothalamic } \\
\text { tract area using tungsten microelectrode } \\
\text { (Nakae } \text { et al., 2011; Zeilig } \text { et al., 2011) }\end{array}$ & $\begin{array}{l}\text { Resembles allodynia and hyperalgesia } \\
\text { Provides useful and novel insights into the } \\
\text { underlying biological mechanisms of SCI }\end{array}$ \\
\hline Canal stenosis & $\begin{array}{l}\text { Is entrapment of the cauda equine and/or lumber } \\
\text { Nerve roots by hypertrophy of osseous and soft } \\
\text { tissue structures surrounding the lumber spinal } \\
\text { cord that reduces blood flow (Sekido et al., 2012) }\end{array}$ & $\begin{array}{l}\text { This model helps clarify pathophysiology of } \\
\text { chronic, light pressure to the spinal cord } \\
\text { (Sekiguchi } \text { et al., 2004) }\end{array}$ \\
\hline
\end{tabular}

Nonetheless, the contusion model has been used in a variety of studies that include: (1), the use of CM101, a polysaccharide derived from group B streptococcus which inhibited inflammatory angiogenesis, protecting axons from Wallerian degeneration and improving functional outcome in mice (Wamil et al., 1998; Nanney et al., 2001) (2), suppression of CD47, an inhibitor of angiogenesis improved functional outcomes in knockout mice (Myers et al., 2011; 2012) (3), implantation of human CNS stem cells after a moderate contusion injury improved locomotor recovery in mice (Hooshmand et al., 2009); and (4), transplantation of Bone Marrow Mesenchymal Stem Cells (BMSCs) also increased motor function in rats by the up-regulation of VEGF expression and induced angiogenesis (Yu et al., 2011).

However, this initial model has been modified to use other devices that bring about compression to injure the cord; such as clip compression, balloon compression, computer controlled contusion and spinal cord displacement. These are all examples that bring about incomplete SCI.

\subsection{Clip Compression}

The clip compression model in some ways resembles the contusion model as the injury is caused by pressure to the cord. The injury is induced using clips calibrated to 
exert a specific force. A force of $50 \mathrm{~g}$ is normally used to produce an outcome that would have a severe response and a force of $35 \mathrm{~g}$ is used to produce an outcome that would have a moderate response. The clip is then closed over the cord for 1 min (Bruce et al., 2002) allowing precise control over the pressure exerted and the time that the pressure is used for, but this model does not truly mimic the injury seen in humans. Despite this the model is reproducible in rats at the thoracic level (Poon et al., 2007).

The clip compression model has also been applied to the cervical region of the cord in rats to evaluate the efficacy of antagonising the Fas receptor using a soluble Fas receptor post-injury (Robins-Steele et al., 2012). This study showed behavioural recovery along with enhanced cell survival, tissue sparing and integrity of descending fibre tracts when soluble Fas was administrated via an intrathecal catheter either 8 or $24 \mathrm{~h}$ post-injury. Clip compression has also been applied to the cord at the thoracic level (Marsh et al., 2002) in rats to test if neutralization of Nerve Growth Factor (NGF) with a fusion protein to Trk-A, blocked the development of autonomic dysreflexia, a life-threatening condition caused by aberrant primary afferent sprouting in the dorsal horn that is NGF-dependent.

The model has also been used to carry out kinematic studies to assess locomotor recovery following spinal cord clip compression in adult rats (Alluin et al., 2011), suggesting that kinematic parameters (e.g., daily training on a treadmill over a six week period) should be taken into account when looking at new strategies to improve locomotor function after SCI.

\subsection{Balloon Compression}

The Balloon Compression model was first described by Tarlov in 1953 and has been modified since then. The method uses different volumes of balloon inflation and different durations of expression (Lim et al., 2007), allowing for a controlled environment. Later methods did not require laminectomy and therefore were noninvasive and like the clip compression model, allowed for precise control of injury parameters. In an initial description of the balloon compression model, an embelectomy catheter was inserted into the epidural space through a hemilaminectomy hole at the vertebral arches and balloons were then inflated with varying amounts of contrast agents, causing direct compression to the spinal cord (Lim et al., 2007). This method was further adapted and improved such that hemilaminectomy was not required, but that balloons were inserted through the lumbosacral space into the epidural space, where balloons were then inflated (Lee et al., 2008). A variety of different species from canine to monkeys (Guizar-Sahagun et al., 2011) have been assessed through this model to gain a controlled compression model of SCI.

\subsection{Computer Controlled Contusion}

A computer controlled contusion model consists of an animal trap that reproducibly delivers a defined weight to the exposed spinal cord, with a computer monitoring the dynamics of the impact (Stokes et al., 1992; Stokes and Jakeman, 2002). The device allows the researcher to take control of the degree of the injury produced and shown that a well controlled contusion injury can be seen observed in mice (Jakeman et al., 2000) as it reduces the variability of the experiment and allows monitoring of biochemical parameters as well as assessments of behavioural and histological outcomes following contusion injury (Ma et al., 2001).

\subsection{Spinal Cord Displacement}

Spinal cord displacement allows the cord to be exposed to a single rapid and calibrated displacement at the site of a laminectomy. The injury is initiated at the tip of a vertical shaft driven by an electromagnetic shaker. Transducers are arranged in series with the shaft recording the patterns of displacement and force during the impact (Jakeman et al., 2000). The results demonstrate that the electromagnetic device can be used to produce a well-controlled contusion injury. The model attempts to regulate trauma impact by controlling displacement length of the spinal cord (Nakae et al., 2011) and therefore helps to reduce outcome variability.

Sensory testing after SCI in rats has been carried out (Detloff et al., 2010) and it is thought that SCI injury impairs sensory systems causing allodynia, showing that early detection of this provoked pain pathway can identify mechanisms that are responsible for its development. Hypothermia improves mobility in rodents and experiments have reported the preservation of neurons immediately after injury and a faster rate of recovery occurs after cervical displacement when hyperthermia is implemented (Lo et al., 2009).

\subsection{Transection Models}

The transection model is referred to as a complete spinal transection which is performed using spring scissors following laminectomy, producing a laceration of the cord. This model may reflect complete SCI in patients (Nakae et al., 2011) but this type of injury is rarely seen in the clinic (Talac et al., 2004; Poon et al., 
2007); however, partial transection (hemisection) is also modelled and has become popular for studies in the mechanisms of pain. Transection models are also increasingly used to model the effects of scaffolds and biomaterials on axon regeneration after injury. For example, a polymer scaffold with rat bone marrow stem cells has been used to promote plasticity and limited regeneration in spinal cords after injury (Kang et al., 2011). Combinatorial therapies have also been used where (Fan et al., 2011) neurotrophic factors have been combined with biomaterials after complete transection of the spinal cord in rats. Enhancing axonal regrowth appears to be a promising therapeutic approach to repair the injured spinal cord. To allow for regeneration, sterile gel foams have been placed between the two ends of transected cords with variable degree of success (Nakae et al., 2011).

Neurotrophic factors have also been used in studies by Garcia-Alias et al. (2011) after a lateral hemisection to the spinal cord, combining NT-3 with Chondroitinase $\mathrm{ABC}$ treatment as it restores plasticity in the adult CNS. They found that these animals displayed inter-limb coordination and improved body stability. Furthermore, Neural Stem/Progenitor Cells (NSPCs) have been used to deliver soluble Nogo66 (Guo et al., 2012) receptor protein (blocks the inhibitory effects of myelin-based inhibitors) and growth factors to rat spinal cord following complete transection. Results show an increase in survival of transplanted NSPCs while soluble Nogo66 enhanced axonal regeneration, although no effect on functional recovery was observed, since a small number of descending corticospinal tract axons grew into the central portions of the bridges. Nogo-66 has been discussed previously by Wei et al. (2010) following hemisection in rats to show the effects of using hyaluronic acid hydrogels modified with Nogo66 receptor antibodies in supporting angiogenesis and inhibiting the glial scar at the lesion site (Wei et al., 2010). Despite the fact that transection is rarely seen in the clinic, these models have served useful purposes in allowing the use of biomaterials, stem cells and neural progenitor cells to show that some of these therapies, when used in combination can restore some degree of function through mainly plasticity-related changes to spinal circuits.

\subsection{Photochemical Models}

This method was first developed by (Watson et al., 1986), which showed a photochemical-based model of SCI and is now widely used to study neurotrauma (Gaviria et al., 2002). To bring about the injury, a dye is used to induce the photochemical reaction by activating an argon laser to produce single oxygen molecules on the endothelial surface of spinal cord vessels. This causes intense platelet responses, vessel occlusion and damage to parenchymal tissues (Hao et al., 1991). The model is reliable and reproducible and does not require mechanical trauma and therefore there is no need for a laminectomy since the injury is caused purely by ischemia. Once the injury has been induced, behavioural studies can be performed.

The model reproduces the phenomenon of secondary lesions such as; cavitation that is seen after SCI. Using this model, motor recovery after photochemical SCI, induced before or after intrathecal injection of bupivacaine (anaesthetic drug belonging to an amino amide group that blocks sodium channels and therefore preventing the influx of sodium resulting in preventing depolarisation) resulted in improved motor recovery in rats (Lopez et al., 2004). The model has also been successfully adapted in the mouse showing that it is reproducible and reliable (Gaviria et al., 2002; Piao et al., 2009). Different exposures to a cold light source correlated with the extent and severity of the injury, while histopathological analysis showed cavity formation in the ischemic environment. How these models relate to the human condition needs further investigation but these studies can model some of the features of the secondary injury phase and thus may be beneficial.

\subsection{Excitotoxic Models}

An excitotoxic model is induced via intraspinal/intrathecal injection of excitotoxins such as, quiscolic acid. The use of excitotoxins produces longlasting spontaneous pain, thermal hyperalgesia and mechanical allodynia but also produce cavity formation, neuronal loss and astrocytic scaring (glial scar tissue which correlates with the general environment observed after SCI). The advantage of this model is that it has the ability to correlate specific areas of tissue damage with behavioral changes (Nakae et al., 2011). Animals that are exposed to SCI using this method do exhibit pain that is much greater than any other model (Leem et al., 2010; Nakae et al., 2011) injected AMPA-metabatrophic receptor agonist quiscolic acid to stimulate injury, resembling ischemic events and cavitation observed after SCI, characteristic of the clinical condition known as posttraumatic Syringomyelia. Intraspinal injection of quiscolic acid has also been used to induce excitotoxic SCI in rats (Bhatoe, 2009) demonstrating pathological changes that correlate with clinical SCI; such as, neuronal loss, haemorrhage and cavitation (Schwartz et al., 1999; Berens et al., 2005). Although the excitotoxic model is a non-traumatic model it displays the characteristic pathological differences that would be seen after clip- 
compression and contusion models that are more commonly used. Therefore, the model is useful in investigating excitotoxic-mediated changes after SCI.

\subsection{Spinothalamic Tract Model}

This model restricts injury to the spinothalamic tract, which is the main pain pathway in animals, using tungsten microelectrodes (Nakae et al., 2011). The model provides useful and novel insights into the underlying biological mechanisms of SCI, resembling some features of SCI in humans including hyperalgesia and allodynia (Wang and Thompson, 2008). The model is particularly useful in studying pain behaviour, as it works with the central pain pathway, although (Finnerup et al., 2007) claimed that the loss of spinothalamic functions in patients with neuropathic pain does not appear to be a predictor for central pain in SCI, but is a contributor.

Zeilig et al. (2011) showed that the hyperexcitabilty of neurones may be due to damage to the spinothalamic tract where the central pain pathway causes a buildup in response. Spinothalamic tract neurones show an increased expression of metabatrophic glutamate receptor subtype 1 (Mills and Hulsebosch, 2002), which parallels the development of hyperalgesia and allodynia, both of which contribute to central pain after injury.

\subsection{Canal Stenosis}

Canal stenosis is described as the entrapment and narrowing of the cauda equine and/or lumbar nerve roots by hypertrophy of osseous and soft tissue structures surrounding the lumbar spinal cord, causing ischemia at the site of injury (Nakae et al., 2011). The model therefore causes demyelination and subsequent axonal degeneration. Canal stenosis can be termed a model (Sekiguchi et al., 2004; Ito et al., 2007), which helps to clarify pathophysiology of chronic, light pressure on the spinal cord. Only recently an animal model has been developed know as, rat Lumbar spinal Canal Stenosis (LCS) model (Sekido et al., 2012) which can be used to study mainly bladder function after injury. Trauma contributes to the primary injury sustained but age can play a major factor (Akuthota et al., 2003) in narrowing the spinal canal. Injury to the nerve does not always occur in this model but factors such as degeneration of neurones, ischemia and inflammation around the site of injury play major contributions to the injury of the nerve. It remains to be seen how useful this model will be in understanding some of the pathological changes that occur after SCI.

\subsection{Limitations of Spinal Cord Injury Models}

As previously discussed, each model presents itself with various limitations with the major holdback being that animal models never truly express the injury seen in humans for a variety of reasons. For example, it may be difficult to assess pain using a contusion model, as sometimes pain behaviour is not always apparent if the weight is released on the specified area from a short distance. The contusion model is also performed mainly in the thoracic region, as cervical contusion can be lifethreatening (Nakae et al., 2011) due to respiratory and cardiovascular functions being compromised at the level of injury (Yisheng et al., 2007). For example, upper cervical SCI can disrupt the transmission of respiratory signals from the brain stem to the phrenic motor neurones (transmit signals to the diaphragm) therefore causing paralysis (Zimmer et al., 2007). Using computer controlled contusion as a method to obtaining reproducible and reliable $\mathrm{SCI}$, it is also is an expensive method due to the sophisticated equipment that is required. The method also produces lesions that is difficult to distinguish between spared and regenerating axons, especially if the focus of the study is axon regeneration (Talac et al., 2004). Although complete transection models are widely used to asses regeneration with the help of biomaterials and scaffolds, it does produce a large scar at the epicentre (Winter et al., 2002) and therefore represents a severe model and so animals require intensive post-operative care (Talac et al., 2004). However, transection models are difficult to standardise if several segments of the cord are removed (Blight, 2000). In addition this model is rarely seen in humans and therefore has no clinical relevance except to evaluate implantation devices and axon regeneration (Talac et al., 2004). Hemisection models however, do not completely cut the corticospinal tract due to the injury being incomplete. It is also difficult to control the extent of injury if SCI is induced through the photochemical method since large areas may be affected by the ischemic environment created as a result of this model.

The anatomical location of injury between experimental animal models and clinical human SCI differ greatly. As discussed above, experimental SCI is potentially dangerous at the cervical level as it may lead to life threatening complications to the animal. SCI at the thoracic level is more commonly used in experimental models, however humans commonly present with SCI at the cervical region (Akhtar et al., 2008) and therefore the site of injury can greatly affect the pathology and the severity of the injury presented in a clinical setting. 
Two other factors play a crucial role in experimental SCI not mimicking the clinical injury presented by humans; laminectomy and anaesthesia. If laminectomy is performed on a patient, it not only increases the local trauma but can cause spinal instability. This can also occur in animal models of SCI as surrounding muscle, bone and ligaments are removed during induction of injury. Removal of specific components at the region of injury can have a major impact and alter the physiological responses to injury. In some ways, laminectomy free methods such as, balloon compression models may mimic the human condition more accurately.

Anaesthesia on the other hand, affects the CNS pathology and recovery following injury, either directly or indirectly (Akhtar et al., 2008). It can affect blood pressure, respiratory rate and metabolism as each individual can react differently under different concentrations of the same anaesthetic. As stated above motor recovery following photochemical SCI being induced before or after intrathecal injection of bupivacaine (Lopez et al., 2004) shows that anaesthesia can affect recovery and functional outcomes after SCI.

Functional outcomes and behavioural assessments between clinical models and experimental models of SCI also vary. It is very easy for human's to express the pain and symptoms that the injury presents but very difficult to do so with animal models. Therefore, specific tests and analysis methods are carried out post-injury to correlate the injury with their behavioural patterns and specific biomarkers. The behavioural patterns often correlate with the severity of the injury produced and is a measurement that is quite reasonable to carry out in a clinical environment but for animal models it is quite limited and indirect (Blight, 2000). The main way that functional outcomes are assessed in animals is by using the BBB score, which is a locomotor activity evaluation, originally developed at the Ohio State University (Basso et al., 1995; 1996). The BBB score evaluates the movements of the hind limb of an animal after injury to express recovery. Although this analysis is reliable and reproducible, researchers have tested it through the severity of the condition (Filho and Molina, 2008), where the BBB score is reproducible in animals with mild severity but as the condition becomes more serve, reproducibility is reduced. While the BBB score only assess hind limb function, it does not take into account pain, bladder and bowel function which are other symptoms that require coordinated spinal cord activity (Akhtar et al., 2008). Other ways of evaluating locomotor recovery are also commonly used, such as grid walking, which tests the animal's ability to deal with challenging limb control problems (Blight, 2000). In patients, sensory assessment can be performed by testing whether they can distinguish between a sharp or dull edge of a pin but this cannot accurately be reproduced in animals and researchers solely attempt to assess sensory function based on the loss of motor functions (Akhtar et al., 2008).

\section{CONCLUSION}

In summary, there is a vast amount of research that is available on different models that are used to present experimental SCI that are also reproducible, reliable and in some ways resemble the injury seen in humans. However, the most common methods of producing an SCI in animal models is; contusion/compression and transection. These models express some of the features of the injury response that is seen in humans and are routinely used in research to assess, pain pathways, biochemical markers, morphology and path physiology. Limitations do exist between clinical and experimental SCI from functional and behavioural assessments to the anatomical location of the injury sustained, but advances in research continue to push forward with many of these limitations still present.

\section{ACKNOWLEDGEMENT}

This study was supported by a BBSRC Doctoral Training Grant (grant no. BB/F017553/1) and the Wellcome Trust (Z.A., grant no. 092539).

\section{REFERENCES}

AASCIN, 2004. American association of spinal cord injury nurses standards of practice--revised 20032004. SCI Nurs., 21: 228-232. PMID: 15794425

Akhtar, A.Z., J.J. Pippin and C.B. Sandusky, 2008. Animal models in spinal cord injury: A review. Rev. Neurosci., $\quad 19$ : $47-60 . \quad$ DOI: 10.1515/REVNEURO.2008.19.1.47

Akuthota, V., P. Lento and G. Sowa, 2003. Pathogenesis of lumbar spinal stenosis pain: Why does an asymptomatic stenotic patient flare? Phys. Med. Rehabil. Clin. N Am., 14: 17-28. PMID: 12622479

Allen, A.R., 1911. Surgery of experimental lesion of spinal cord equivalent to crush injury of fracture dislocation of spinal column: A preliminary report. J. Am. Med. Assoc., 57: 878-880. DOI: 10.1001/Jama.1911.04260090100008 
Alluin, O., S. Karimi-Abdolrezaee, H. Delivet-Mongrain, H. Leblond and M.G. Fehlings et al., 2011. Kinematic study of locomotor recovery after spinal cord clip compression injury in rats. J. Neurotrauma, 28: 1963-1981. DOI: 10.1089/neu.2011.1840

Basso, D.M., M.S. Beattie and J.C. Bresnahan, 1995. A sensitive and reliable locomotor rating scale for open field testing in rats. J. Neurotrauma, 12: 1-21. PMID: 7783230

Basso, D.M., M.S. Beattie, J.C. Bresnahan, D.K. Anderson and A.I. Faden et al., 1996. MASCIS evaluation of open field locomotor scores: Effects of experience and teamwork on reliability. Multicenter animal spinal cord injury study. J. Neurotrauma, 13: 343-359. PMID: 8863191

Behrmann, D.L., J.C. Bresnahan and M.S. Beattie, 1993. A comparison of YM-14673, U-50488H and nalmefene after spinal cord injury in the rat. Exp. Neurol., 119: 258-267. PMID: 8432363

Berens, S.A., D.C. Colvin, C.G. Yu, R.P. Yezierski and T.H. Mareci, 2005. Evaluation of the pathologic characteristics of excitotoxic spinal cord injury with MR imaging. Am. J. Neuroradiol., 26: 1612-1622. PMID: 16091503

Bhatoe, H.S., 2009. Posttraumatic syringomyelia. Ind. J. Neurotrauma, 6: 21-26. DOI: 10.1016/S09730508(09)80023-3

Blight, A.R., 2000. Animal models of spinal cord injury. Top. Spinal Cord Injury Rehabil., 6: 1-13. DOI: 10.1310/2XNY-A824-UCTF-EN4D,

Bracken, M.B., 2012. Steroids for acute spinal cord injury. Cochrane Database Syst. Rev., 1: CD001046-CD001046. PMID: 22258943

Bruce, J.C., M.A. Oatway and L.C. Weaver, 2002. Chronic pain after clip-compression injury of the rat spinal cord. Exp. Neurol., 178: 33-48. PMID: 12460606

Byrnes, K.R., S.T. Fricke and A.I. Faden, 2010. Neuropathological differences between rats and mice after spinal cord injury. J. Magn. Reson. Imag., 32: 836-846. PMID: 20882614, DOI: 10.1002/jmri.22323

Cadotte, D.W. and M.G. Fehlings, 2011. Spinal cord injury: A systematic review of current treatment options. Clin. Orthop. Relat. Res., 469: 732-741. PMID: 21080129, DOI: 10.1007/s11999-010-1674-0

Davoody, L., R.L. Quiton, J.M. Lucas, Y. Ji and A. Keller et al., 2011. Conditioned place preference reveals tonic pain in an animal model of central pain. J. Pain, 12: 868-874. PMID: 21515090
Detloff, M.R., L.M. Clark, K.J. Hutchinson, A.D. Kloos and L.C. Fisher et al., 2010. Validity of acute and chronic tactile sensory testing after spinal cord injury in rats. Exp. Neurol., 225: 366-376. PMID: 20643128

Echeverry, S., X.Q. Shi, S. Rivest and J. Zhang, 2011. Peripheral nerve injury alters blood-spinal cord barrier functional and molecular integrity through a selective inflammatory pathway. J Neurosci., 31: 10819-10828. PMID: 21795534

Fairbanks, C.M., D. Freedman and C. Kahn, 2000. The role of effective mentors in learning to teach. J. Teacher Educ., 51: 102-112.

Fan, J., H. Zhang, J. Xiaodan, Z. Xiao and B. Chen et al., 2011. Neural regrowth induced by PLGA nerve conduits and neurotrophin-3 in rats with complete spinal cord transection. J. Biomed. Mater. Res., Part B, Applied Biomater., 97: 271-277. PMID: 21384547

Filho, T.E.B. and A.E. Molina, 2008. Analysis of the sensitivity and reproducibility of the Basso, Beattie, Bresnahan (BBB) scale in Wistar Rats. Clinics, 63: 103-108. PMID: 18305873

Finnerup, N.B., L. Sorensen, F. Biering-Sørensen, I.L. Johannesen and T.S. Jensen, 2007. Segmental hypersensitivity and spinothalamic function in spinal cord injury pain. Exp. Neurol., 207: 139-149. PMID: 17628539

French, D.D., R.R. Campbell, S. Sabharwal, A.L. Nelson and P.A. Palacios et al., 2007. Health care costs for patients with chronic spinal cord injury in the Veterans Health Administration. J. Spinal Cord Med., 30: 477-481. PMID: 18092564

Garcia-Alias, G., H.A. Petrosyan, L. Schnell, P.J. Horner and W.J. Bowers et al., 2011. Chondroitinase ABC combined with neurotrophin NT-3 secretion and NR2D expression promotes axonal plasticity and functional recovery in rats with lateral hemisection of the spinal cord. J. Neurosci., 31: 17788-17799. DOI: 10.1523/JNEUROSCI.4308-11.2011

Gaviria, M., H. Haton, F. Sandillon and A. Privat, 2002. A mouse model of acute ischemic spinal cord injury. J. Neurotrauma, 19: 205-221. PMID: 11893023

Gorio, A., L. Madaschi, B.D. Stefano, S. Carelli and A.M.D. Giulio et al., 2005. Methylprednisolone neutralizes the beneficial effects of erythropoietin in experimental spinal cord injury. Proc. Natl. Acad. Sci. U.S.A., 102: 16379-16384. PMID: 16260722 
Gruner, J.A., 1992. A monitored contusion model of spinal cord injury in the rat. J. Neurotrauma, 9: 123126. PMID: 1404425

Guizar-Sahagun, G., I. Grijalva, B. Hernandez-Godinez, R.E. Franco-Bourland and L. Cruz-Antonio et al., 2011. New approach for graded compression spinal cord injuries in Rhesus macaque: Method feasibility and preliminary observations. J. Med. Primatol., 40: 401-413. PMID: 21732951

Guo, X., T. Zahir, A. Mothe, M.S. Shoichet and C.M. Morshead et al., 2012. The effect of growth factors and soluble Nogo-66 receptor protein on transplanted neural stem/progenitor survival and axonal regeneration after complete transection of rat spinal cord. Cell Trans., 21: 1177-1197. PMID: 22236767

Hao, J.X., X.J. Xu, H. Aldskogius, A. Seiger and Z. Wiesenfeld-Hallin, 1991. Allodynia-like effects in rat after ischaemic spinal cord injury photochemically induced by laser irradiation. Pain, 45: 175-185. PMID: 1652116

Hooshmand, M.J., C.J. Sontag, N. Uchida, S. Tamaki and A.J. Anderson et al., 2009. Analysis of hostmediated repair mechanisms after human CNS-stem cell transplantation for spinal cord injury: Correlation of engraftment with recovery. PloS One, 4: e5871- e5871. PMID: 19517014

Ito, T., S. Ohtori, G. Inoue, T. Koshiand H. Doya et al., 2007. Glial phosphorylated p38 MAP kinase mediates pain in a rat model of lumbar disc herniation and induces motor dysfunction in a rat model of lumbar spinal canal stenosis. Spine, 32: 159-167. PMID: 17224809

Jakeman, L.B., Z. Guan, P. Wei, R. Ponnappan and R. Dzwonczyk et al., 2000. Traumatic spinal cord injury produced by controlled contusion in mouse. J. Neurotrauma, 17: 299-319. PMID: 10776914

James, N.D., K. Bartus, J. Grist, D.L. Bennett and S.B. McMahon et al., 2011. Conduction failure following spinal cord injury: Functional and anatomical changes from acute to chronic stages. J. Neuroscience, 31: 18543-18555. PMID: 22171053

Kang, K.N., J.Y. Lee, Y.D. Kim, B.N. Lee and H.H. Ahn et al., 2011. Regeneration of completely transected spinal cord using scaffold of poly(D,L-lactide-coglycolide)/small intestinal submucosa seeded with rat bone marrow stem cells. Tissue Eng. Part A, 17: 2143-2152. PMID: 21529281
Lee, J.H., C.B. Choi, D.J. Chung, E.H. Kang and H.S. Chang et al., 2008. Development of an improved canine model of percutaneous spinal cord compression injury by balloon catheter. J. Neurosci. Meth., 167: 310-316. PMID: 17870181

Lee, J.Y., H.S. Kim, H.Y. Choi, T.H. Oh and T.Y. Yune, 2012. Fluoxetine inhibits matrix metalloprotease activation and prevents disruption of blood-spinal cord barrier after spinal cord injury. Brain, 135: 2375-2389. PMID: 22798270

Leem, Y.J., J.W. Joh, K.W. Joeng, J.H. Suh and J.W. Shin et al., 2010. Central pain from excitotoxic spinal cord injury induced by intraspinal NMDA injection: A pilot study. Korean J. Pain, 23: 109115. PMID: 20556212

Lim, J.H., C.S. Jung, Y.E. Byeon, W.H. Kim AND J.H. Yoon et al., 2007. Establishment of a canine spinal cord injury model induced by epidural balloon compression. J. Vet. Sci., 8: 89-94. PMID: 17322779

Lo, Jr., T.P., K.S. Cho, M.S. Garg, M.P. Lynch and A.E. Marcillo et al., 2009. Systemic hypothermia improves histological and functional outcome after cervical spinal cord contusion in rats. J. Comput. Neurol., 514: 433-448. PMID: 19350644

Lopez, S., A. Privat, N. Bernard, F. Ohanna and C. Vergnes et al., 2004. Intrathecal bupivacaine protects against extension of lesions in an acute photochemical spinal cord injury model. Canad. J. Anaesthesia, 51: 364-372. DOI: 10.1007/BF03018241

Ma, M., D.M. Basso, P. Walters, B.T. Stokesa and L.B. Jakemana, 2001. Behavioral and histological outcomes following graded spinal cord contusion injury in the C57Bl/6 mouse. Exp. Neurol., 169: 239-254. DOI: 10.1006/exnr.2001.7679

Marsh, D.R., S.T. Wong, S.O. Meakin, J.I.S. MacDonald and E.F. Hamilton et al., 2002. Neutralizing intraspinal nerve growth factor with a trkA-IgG fusion protein blocks the development of autonomic dysreflexia in a clip-compression model of spinal cord injury. J. Neurotrauma, 19: 1531-1541. DOI: 10.1089/089771502762300201

Merola, A., M.F. O’Brien, B.A. Castro, D.A. Smith and J.M. Eule et al., 2002. Histologic characterization of acute spinal cord injury treated with intravenous methylprednisolone. J. Orthop. Trauma, 16: 155161. PMID: 11880777 
Middleton, J., Y. Tran and A. Craig, 2007. Relationship between quality of life and self-efficacy in persons with spinal cord injuries. Arch. Phys. Med. Rehabil., 88: 1643-1648. DOI: 10.1016/j.apmr.2007.09.001

Middleton, J.W., A. Dayton, J. Walsh, S.B. Rutkowski and G. Leong et al., 2012. Life expectancy after spinal cord injury: A 50-year study. Spinal Cord, 50: 803-811. PMID: 22584284

Mills, C.D. and C.E. Hulsebosch, 2002. Increased expression of metabotropic glutamate receptor subtype 1 on spinothalamic tract neurons following spinal cord injury in the rat. Neurosci. Lett., 319: 5962. DOI: 10.1016/S0304-3940(01)02551-4

Myers, S.A., W.H. DeVries, K.R. Andresa, M.J. Gruenthala and S.R. Whittemorea et al., 2011. CD47 knockout mice exhibit improved recovery from spinal cord injury. Neurobiol. Dis., 42: 21-34. DOI: 10.1016/j.nbd.2010.12.010

Myers, S.A., W.H. Devries, M.J. Gruenthal, K.R. Andres and T. Hagg et al., 2012. Sildenafil improves epicenter vascular perfusion but not hindlimb functional recovery after contusive spinal cord injury in mice. J. Neurotrauma, 29: 528-538. PMID: 21970599

Nakae, A., K. Nakai, K. Yano, K. Hosokawa and M. Shibata et al., 2011. The animal model of spinal cord injury as an experimental pain model. J. Biomed. Biotechnol., 2011: 939023-939033. DOI: 10.1155/2011/939023

Nanney, L.B., B.D. Wamil, J. Whitsitt, N.L. Cardwell and J.M. Davidson et al., 2001. $\mathrm{CM}_{101}$ stimulates cutaneous wound healing through an anti-angiogenic mechanism. Angiogenesis, 4: 61-70. DOI: 10.1023/A:1016752925761

Ogungbo, B., 2011. Anterior decompression, fusion and plating in cervical spine injury: Early experience in Abuja, Nigeria. Surg. Neurol. Int., 2: 156-156. PMID: 22140641

Pandya, K.A., K.A. Weant and A.M. Cook, 2010. Highdose methylprednisolone in acute spinal cord injuries: Proceed with caution. Orthopedics, 33: 327-331. PMID: 20507035

Piao, M.S., J.K. Lee, J.W. Jang, S.H. Kim and H.S. Kim et al., 2009. A mouse model of photochemically induced spinal cord injury. J. Korean Neuros. Soc., 46: 479-483. DOI: 10.3340/jkns.2009.46.5.479
Poon, P.C., D. Gupta, M.S. Shoichet and C.H. Tator, 2007. Clip compression model is useful for thoracic spinal cord injuries: Histologic and functional correlates. Spine, 32: 2853-2859. DOI: 10.1097/BRS.0b013e31815b7e6b

Robins-Steele, S., D.H. Nguyen and M.G Fehlings, 2012. The delayed post-injury administration of soluble Fas receptor attenuates post-traumatic neural degeneration and enhances functional recovery after traumatic cervical spinal cord injury. J. Neurotrauma, 20: 1586-1599. PMID: 22260324

Schwartz, E.D., R.P. Yezierski, P.M. Pattany, R.M. Quencer and R.G. Weaver, 1999. Diffusion-weighted MR imaging in a rat model of syringomyelia after excitotoxic spinal cord injury. Am. J. Neuroradiol., 20: 1422-1428. PMID: 10512223

Sekido, N., A. Jyoraku, H. Okada, D. Wakamatsu and H. Matsuya et al., 2012. A novel animal model of underactive bladder: Analysis of lower urinary tract function in a rat lumbar canal stenosis model. Neurourol. Urodynam., 31: 1190-1196. DOI: 10.1002/nau.21255

Sekiguchi, M., S. Kikuchi and R.R. Myers, 2004. Experimental spinal stenosis: Relationship between degree of cauda equina compression, neuropathology and pain. Spine, 29: 1105-1111. PMID: 15131438

Sharma, A., 2012. Pharmacological management of acute spinal cord injury. J. Assoc. Phys. India, 60: 13-18.

Stokes, B.T. and L.B. Jakeman, 2002. Experimental modelling of human spinal cord injury: A model that crosses the species barrier and mimics the spectrum of human cytopathology. Spinal Cord, 40: 101-109. PMID: 11859436

Stokes, B.T., D.H. Noyes and D.L. Behrmann, 1992. An electromechanical spinal injury technique with dynamic sensitivity. J. Neurotrauma, 9: 187-195. DOI: 10.1089/neu.1992.9.187

Talac, R., J.A. Friedman, J.M. Moore, L. Lu and E. Jabbari et al., 2004. Animal models of spinal cord injury for evaluation of tissue engineering treatment strategies. Biomaterials, 25: 1505-1510. DOI: 10.1016/S0142-9612(03)00497-6

Wamil, A.W., B.D. Wamil and C.G. Hellerqvist, 1998. CM101-mediated recovery of walking ability in adult mice paralyzed by spinal cord injury. National Acad. Sci., 95: 13188-13193. DOI: 10.1073/pnas.95.22.13188 
Wang, G. and S.M. Thompson, 2008. Maladaptive homeostatic plasticity in a rodent model of central pain syndrome: Thalamic hyperexcitability after spinothalamic tract lesions. J. Neurosc., 28: 1195911969. DOI: 10.1523/JNEUROSCI.3296-08.2008

Watson, B.D., R. Prado, W.D. Dietrich, M.D. Ginsberg and B.A. Green, 1986. Photochemically induced spinal cord injury in the rat. Brain Res., 367: 296300. DOI: 10.1016/0006-8993(86)91606-9

Wei, Y.T., Y. He, C.L. Xu, Y. Wang and B.F. Liu et al., 2010. Hyaluronic acid hydrogel modified with nogo66 receptor antibody and poly-L-lysine to promote axon regrowth after spinal cord injury. J. Biomed. Mater. Res., 95: 110-117. DOI: 10.1002/jbm.b.31689

Winter, D.F., M. Oudega, A.J. Lankhorst, F.P. Hamers and B. Blits et al., 2002. Injury-induced class 3 semaphorin expression in the rat spinal cord. Exp. Neurol., 175: 61-75. PMID: 12009760

Yezierski, R.P., S. Liu, G.L. Ruenes, K.J. Kajander and K.L. Brewerl, 1998. Excitotoxic spinal cord injury: Behavioral and morphological characteristics of a central pain model. Pain, 75: 141-155. PMID: 9539683
Yisheng, W., Z. Fuying, W. Limin, L. Junwei and P. Guofu et al., 2007. First aid and treatment for cervical spinal cord injury with fracture and dislocation. Ind. J. Orthop., 41: 300-304. DOI: 10.4103/0019-5413.36991

Yu, D., G. Lu, G. Li, X. Zhi and Z. Fan et al., 2011. Effects of bone marrow mesenchymal stem cells transplantation on expression of vascular endothelial growth factor gene and angiogenesis after spinal cord injury in rats. Chin. Zhongguo Xiu Fu Chong Jian Wai Ke Za Zhi, 25: 837-841. PMID: 21818951

Zeilig, G., S. Enosh, D. Rubin-Asher, B. Lehr and R. Defrin, 2011. The nature and course of sensory changes following spinal cord injury: Predictive properties and implications on the mechanism of central pain. Brain, 135: 418-430. DOI: 10.1093/brain/awr270

Zhang, N., Y. Yin, S.J. Xu, Y.P. Wu and W.S. Chen, 2012. Inflammation and apoptosis in spinal cord injury. Ind. J. Med. Res., 135: 287-296. PMID: 22561613

Zimmer, M.B., K. Nantwi and H.G. Goshgarian, 2007. Effect of spinal cord injury on the respiratory system: Basic research and current clinical treatment options. J. Spinal Cord Med., 30: 319-330. PMID: 17853653 